\title{
CORRESPONDENCE
}

\section{Two Probable Shell Trumpets from Ontario}

In making investigations pertaining to the question of possible unreported finds in the Mississippi Valley of large conch shells with their spires cut down for the evident purpose of use as a shell trumpet, I wrote the Buffalo Museum of Science. The primary reason was to attempt to trace the actual specimens of Busycon perversum shells found at Alton, Illinois, and noted in my article published in this journal, Vol. II, No. 1. Unfortunately, these specimens were not deposited in that institution. However, Mrs. Imogene C. Robertson, Assistant

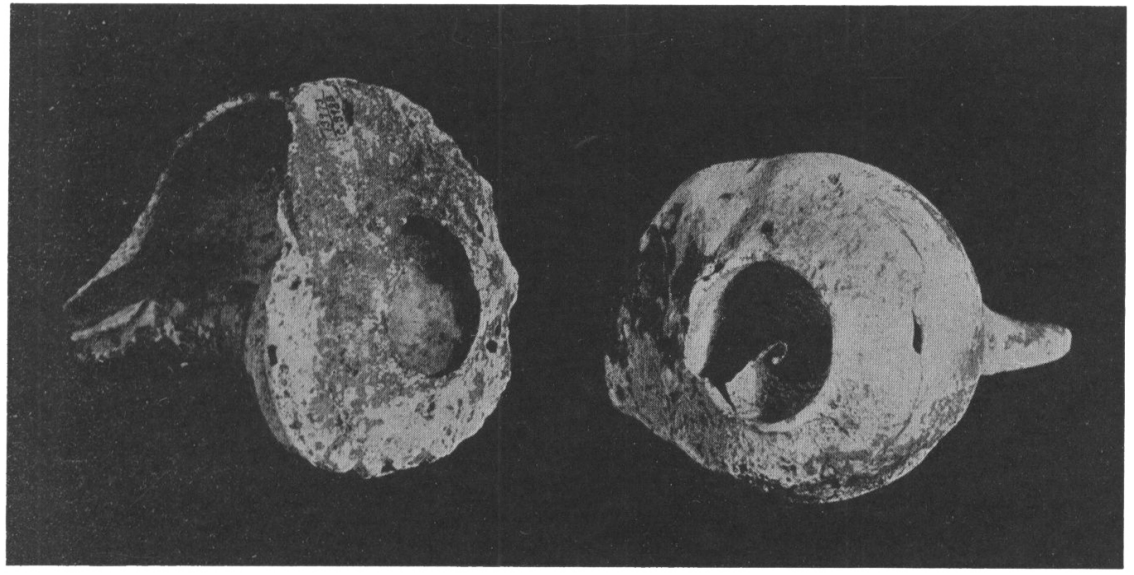

Curator of Biology and Registrar of the Buffalo Museum of Science, became interested in my attempt. Going over the museum collection, she was able to find two specimens of Busycon perversum, as illustrated in the accompanying figure, which has been made available through the courtesy of the Buffalo Museum of Science. Hence, the credit of this find should go entirely to Mrs. Robertson, without whose whole-hearted interest these shells would have remained unnoticed. Possibly others have been found, without any special significance having been attached to this characteristic removal of the spire. As such a modification of these conch shells completely ruins them for any other purpose except blowing through the opening, it would appear to me that such a find, added to the one already reported, should tend to establish the use of shell trumpets in these two areas, possibly before the advent of the whites.

Mrs. Robertson writes as follows: "In looking over our material, however, I find two well-preserved specimens of the same species labeled 'Neuter Cemetery, Humberston, Ont.' These both have the apex of the spire cut off and edges smoothed in exactly similar fashion and may have been used as trumpets." 
However, granting that further finds of a similar nature should firmly establish the pre-Columbian use of shell trumpets in parts of the mound-building territory, it seems to me that we will then have solved one question only to raise another more important one. Supposing that the use of such trumpets existed in the period antedating by a reasonably short time the advent of the early New England settlers, then how is it we do not seem to be able to find the slightest reference to such a use in the myths, folklore and legends of the tribes inhabiting this area when discovered? And, if no reference does exist, would it not be reasonable to suppose that when such shell trumpets are found in this mound territory, it might be an indication of a considerable age for a site, or even a different culture? ${ }^{207}$

To my mind, the line of research opened up by this question of shell trumpets in this particular territory offers a most intriguing problem. To attempt to cover it properly necessitates the coöperation of the many readers of AMERICAN ANTIQUITy, particularly those specializing in the archaeology of this large area. Their specialized knowledge, now that the matter has been called to their attention, should lead to the ultimate solution of the question.

What is first required is an examination of those conch shells stored in institutions, such as Mrs. Robertson was so prompt in undertaking. By plotting such finds on our maps we would soon be able to note graphically which groups of mounds had such trumpets, and coördinate this data with the finds of other worked marine shells, such as Busycon perversum containers, Olivella and Marginella beads, Oliva sayana pendants, and so forth. With such information as a basis, it should be possible to establish tentative trade routes, separate the various cultures, and possibly, in time, lay the foundation for the beginning of a chronological outline. Specimens of marine shells from each section would, perhaps, permit me, by a study of their relative degree of disintegration, to work out such a tentative chart.

Will our readers now assist in this project? From the spontaneous spirit of coöperation shown in the archeo- and ethno-conchology research, I believe that they will do so.

Henry J. Boekelman

Louisiana State Museum

New Orleans, Louisiana

\section{Culture Identity of the Ozark "Top Layer"}

In Volume 26, No. 1; pp. 1-21, of the American Anthropologist, n.s., Mr. M. R. Harrington briefly described the salient features of the remains found in

${ }^{207}$ A. L. Kroeber has already shown us how it would appear that at Chincha, Peru, one culture (the earlier) apparently ignored, or paid but slight attention to the Spondylus princeps, whereas the following one (the Inca) quite evidently held this shell in the highest religious esteem, the latter confirmed historically by Spanish chroniclers at the period of the conquest of Peru. Other similar examples from various parts of the world can be found in my files. 